\title{
The "gatekeeper" residue influences the binding mode of acetyl indoles to bromodomains
}

Andrea Unzue,${ }^{[\mathrm{a}]}$ Hongtao Zhao,${ }^{[\mathrm{b}]}$ Graziano Lolli, ${ }^{[\mathrm{b}]}$ Jing Dong, ${ }^{[\mathrm{b}]}$ Jian Zhu, ${ }^{[\mathrm{b}]}$ Melanie Zechner, ${ }^{[\mathrm{a}]}$ Aymeric Dolbois, ${ }^{[\mathrm{a}]}$ Amedeo Caflisch, ${ }^{*[\mathrm{~b}]}$ Cristina Nevado*[a]

Department of Chemistry ${ }^{[\mathrm{a}]}$ and Department of Biochemistry, ${ }^{[\mathrm{b}]}$ University of Zürich Winterthurerstrasse 190, CH-8057 Zürich, Switzerland.

KEYWORDS CREBBP, BAZ2B, BRPF1b, bromodomain crystal structure, scaffold hopping, docking

\begin{abstract}
Small-molecule hits for the bromodomains of CREBBP and BAZ2B have been identified by scaffold hopping followed by docking of a set of about 200 compounds containing the acetyl indole scaffold. Chemical synthesis of nearly 30 derivatives has resulted in ligands of representatives of three subfamilies of human bromodomains with favorable ligand efficiency. The X-ray crystal structures of three different bromodomains (CREBBP, BAZ2B, and BRPF1b) in complex with acetyl indole derivatives reveal the influence of the gatekeeper residue on the orientation of small-molecule ligands in the acetyl lysine binding site.
\end{abstract}

\section{Nomenclature}

Capital letters are used to label generic chemical blueprints. Roman numbers are used to designate commercially available compounds. Arabic numbers are used for synthetic intermediates and self-made products. 


\section{Introduction}

Acetylation of lysine residues is an important post-translational modification of histone proteins that contributes to the regulation of chromatin structure and transcription. ${ }^{1,2}$ Bromodomains are protein modules with four-helix bundle topology that specifically recognize ("read") acetylated lysine residues, as well as butyryllysine and crotonyllysine, ${ }^{3}$ and are considered protein targets of interest for the development of chemical probes and clinical tools to treat cancer, inflammation and other diseases. ${ }^{4-8}$

The BET (bromodomain and extra terminal) subfamily $(\mathrm{BRD} 2 / 3 / 4 / \mathrm{T})$ has been widely addressed, and as a consequence, several potent and selective inhibitors have been developed, some of which are currently undergoing clinical trials for the treatment of NUT midline carcinoma (NMC), solid tumors, leukaemia, lymphoma, haematological malignancies, atherosclerosis and type II diabetes. ${ }^{7,9,10}$ In contrast, the specific function and potential pharmacological relevance of other bromodomains, including CREBBP, EP300, BRD7/9, and BAZ2B, is much less understood, and thus, small molecule inhibitors will be valuable tools to unravel their biological roles.

The bromodomains of EP300 and CREBBP, which belong to the same subfamily and share $96 \%$ sequence identity, ${ }^{11}$ play important roles in DNA replication and repair, cell growth and cell cycle regulation and genomic stability. ${ }^{12,13}$ As an example, EP300 and CREBBP are able to acetylate p53 on its K382 residue through the HAT domain upon extracellular stress or DNA damage and they are also known to specifically bind to acetylated p53 via their bromodomain module. ${ }^{14}$ As a consequence, changes in the p53-dependent activation of target genes result in cell cycle arrest, senescence or apoptosis. ${ }^{15-17}$ On the one hand, chromosome translocations resulting in gene fusions containing CREBBP or EP300 have been linked to leukemias and lymphomas. ${ }^{18,19}$ On the other hand, CREBBP and EP300 
are mutated in solid tumors and B-cell lymphoma, suggesting they possess a tumor suppressing role. ${ }^{13,20}$ Thus, because both oncogene or tumor suppressor roles have been reported for CREBBP and EP300, ${ }^{18,21}$ the development of chemical probes will be instrumental for the analysis of their biological function(s).

The bromodomains of BRD7 and BRD9 belong to the same subfamily and share $72 \%$ similarity. ${ }^{22}$ Both BRD7 and BRD9 are part of the SWI/SNF (SWItch/Sucrose NonFermentable) chromatin remodelling complex, which plays a key role in the regulation of gene expression. ${ }^{23-25}$ Recent reports have linked BRD9 to oncology, including non-small cell lung cancer ${ }^{26}$ and cervical cancer. ${ }^{27}$ Its paralogue, BRD7, is frequently down-regulated in cancer $^{28-30}$ and is able to regulate the tumor suppressor protein $\mathrm{p} 53 .{ }^{31-33}$ The bromodomain of BRPF1b (bromodomain-PHD finger protein 1b) belongs to the same subfamily as BRD7 and BRD9. Despite the function of the BRPF1b bromodomain not being yet fully understood, the availability of BRPF1b ligands might help elucidating its role. ${ }^{34-36}$

BAZ2B (bromodomain adjacent to zinc finger domain 2B) is another bromodomaincontaining protein whose role in physiology and disease is not clear. Biophysical screening of a library of 1300 fragments resulted in the identification of 10 small molecules that bind in the micromolar range to BAZ2B. ${ }^{37}$ Recently, the first submicromolar selective CREBBP, ${ }^{11,38}$, ${ }^{39} \mathrm{BAZ2B}^{40,41}$ and BRD7/922,42, 43 inhibitors have been reported.

Here we present the result of a combined scaffold hopping and docking approach that has enabled the discovery of acetyl indoles as ligands of the bromodomains of CREBBP, BAZ2B, BRPF1b and/or BRD9, which belong to three different subfamilies that lie outside of the BET bromodomain subfamily. A comparative analysis of four crystal structures of bromodomain/acetyl indole complexes show the importance of the so-called gatekeeper residue on the binding mode of the ligand. 


\section{Results and Discussion}

\section{In silico screening by scaffold hopping and docking}

In the past few years, our groups have successfully identified several low $\mu \mathrm{M}$ to $\mathrm{nM}$ kinase $\mathrm{e}^{4-}$ 47 and bromodomain ${ }^{39,48,49}$ inhibitors by high-throughput virtual screening campaigns. In this work, we decided to dock a small subset of compounds containing a moiety identified by scaffold hopping (see Materials and Methods). First, the ZINC all-now library was decomposed into about 600,000 fragments retaining key functional groups. ${ }^{46}$ These fragments were queried by the indolizine fragment $\mathbf{A}$, which is present in the potent BAZ2B ligand GSK2801 ${ }^{41}$ and more recently in BRD7 and BRD9 ligands. ${ }^{22}$ The acetyl indole B was identified as the top ranking fragment with an activity-oriented fingerprint similarity of 0.975 with respect to A. The high similarity is due to almost identical geometry and connecting vectors in the fragments $\mathbf{A}$ and $\mathbf{B}$ (Figure 1).

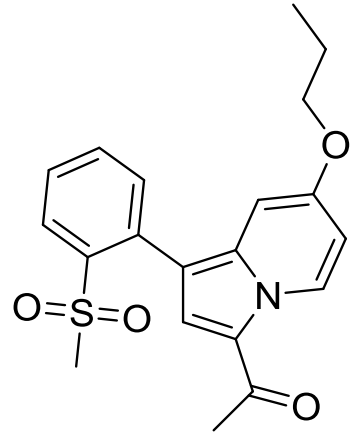

GSK2801

$\mathrm{K}_{\mathrm{D}} \mathrm{BAZ2A}=257 \mathrm{nM}$

$K_{D} B A Z 2 B=136 \mathrm{nM}$

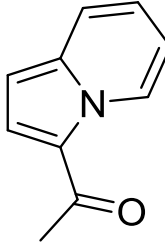

A

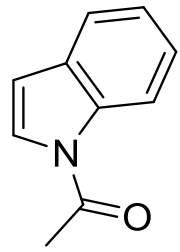

B

Figure 1. (Left) GSK2801, a nanomolar chemical probe for BAZ2A and BAZ2B bromodomains. $^{22,41}$ (Right) Core-fragment hopping by activity-oriented fingerprint using fragment $\mathbf{A}$ as the query molecule. $\mathbf{A}$ and $\mathbf{B}$ respresent generic chemical blueprints. 
In a second step, we retrieved about 200 commercially available compounds containing fragment B. As in our previous fragment-based virtual screening approach, ${ }^{46,} 48,49$ the retrieved compounds were docked into crystal structures of the targets, namely, the bromodomains of CREBBP (PDB code 4A9K) and BAZ2B (PDB code 3Q2F). An in-house developed program for automatic docking was used. ${ }^{48,}$ 50-52 The docking poses were subsequently re-scored by a transferable scoring function (see Materials and Methods). ${ }^{45,50-54}$ Finally, 14 molecules were selected for experimental validation by means of a competition binding assay. ${ }^{55,} 56$ At $50 \mu \mathrm{M}$ concentration, seven compounds showed significant competition (i.e., a percentage of residual binding of CREBBP to the acetylated histone peptide below $70 \%$ with respect to the DMSO control, Figure 2), which corresponds to a hit rate of $50 \%$ for the in silico screening approach based on scaffold hopping and docking. The most active compound I exhibits an equilibrium dissociation constant $\left(\mathrm{K}_{\mathrm{d}}\right)$ of $20 \mu \mathrm{M}$ for CREBBP. Using the same threshold of $70 \%$ as for CREBBP, the hit rate for BAZ2B was $29 \%$ (Figure 2). Interestingly, at $50 \mu \mathrm{M}$ concentration, only compound VI shows significantly higher affinity for BAZ2B than CREBBP. 


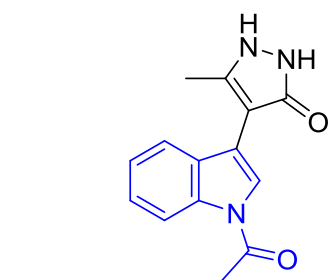

$\begin{array}{ll} & \text { I } \\ \text { CREBBP } & 2.2[20 \mu \mathrm{M}] \\ \text { BAZ2B } & 51\end{array}$

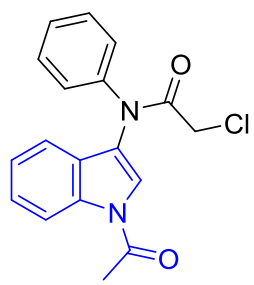

$\begin{array}{ll} & \text { VI } \\ \text { CREBBP } & 65 \\ \text { BAZ2B } & 20[>50 \mu \mathrm{M}]\end{array}$

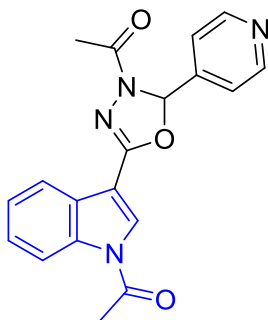

II

51

100

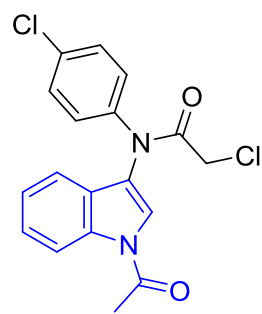

VII

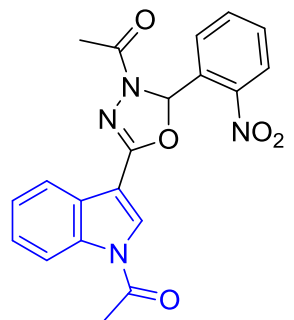

III

56

100<smiles>CC(=O)n1cc2c3c(cccc31)C(=O)SC2C[N+](=O)[O-]</smiles>

VIII

61

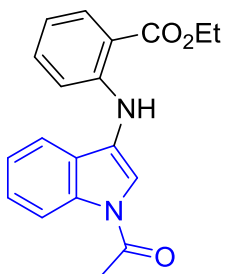<smiles>COC(=O)C(=O)Cc1cn(C(C)=O)c2ccccc12</smiles>

IV

20

81

28

82

Figure 2. Binding affinity and 2D structures of acetyl indole derivatives I-VIII identified by core-fragment hopping and docking. The values are percentage of residual binding of the CREBBP or BAZ2B bromodomain to an acetylated histone peptide at $50 \mu \mathrm{M}$ compound concentration with respect to the DMSO control. Thus, lower percentages indicate higher affinity of the compound. Values in brackets are equilibrium dissociation constants $\left(\mathrm{K}_{\mathrm{d}}\right)$ determined by two independent dose-response measurements of 11 doses each. Compounds II, III, and VIII were measured as racemic mixture. All values were determined by the BROMOscan competition binding assay. ${ }^{55,56}$ Roman numbers I-VIII designate commercially available compounds.

\section{Binding mode of compound I: Validation by X-ray protein crystallography}

The opposite selectivity towards CREBBP and BAZ2B observed for compounds I and VI (Figure 2) prompted us to study their binding mode. While we could not solve the structure with compound VI, the crystal structure of CREBBP in complex with compound I was 
solved at $2.0 \AA$ resolution (Figure 3, in green, PDB code 4TS8), which revealed an overall binding mode essentially identical to the docked pose of compound I (Figure 3, in blue). The binding of compound $\mathbf{I}$ in CREBBP is characterized by a lipophilic sandwich of its bicyclic core between residues Phe1111, Val1174 and Ala1164 on one side, and Val1115, Leu1120 and Ile1 122 on the other side of the binding pocket. The carbonyl oxygen of the acetyl-indole acts as the acetylated lysine mimic and is engaged in hydrogen bonding interactions with the side chains of the conserved Asn1168 (BC loop) and Tyr1125 (ZA loop) where the latter is bridged by a water molecule. Another four water molecules present at the bottom of the pocket are conserved. In addition, there is a water molecule bridging the dihydro-pyrazole ring and the guanidinium group of Arg1173 (Figure 3).

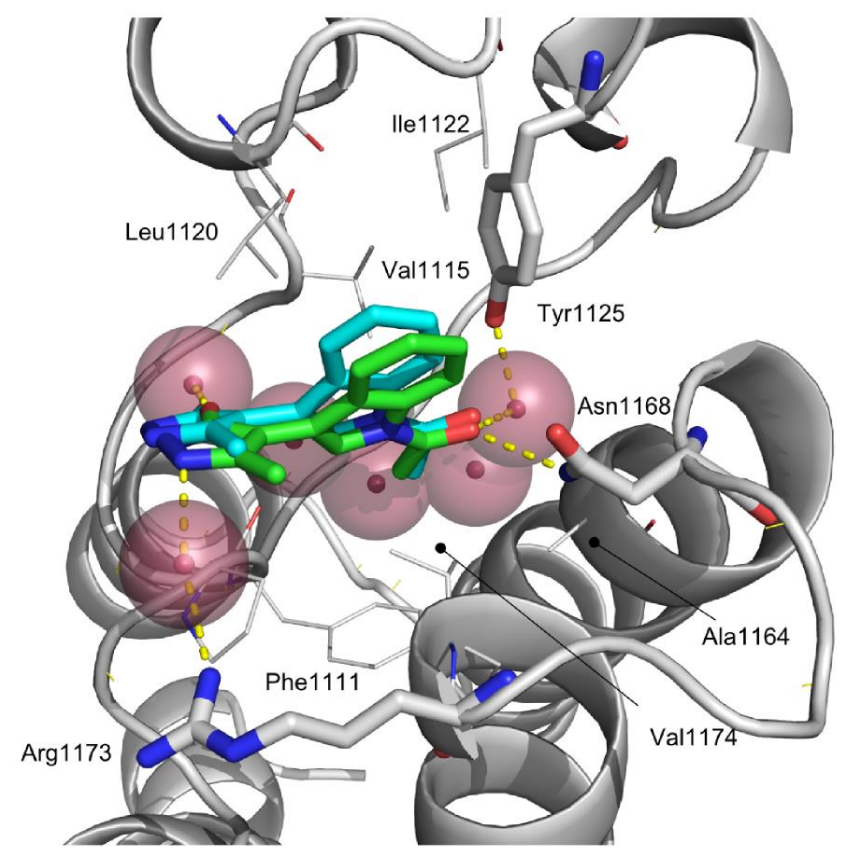

Figure 3. Crystal structure (green) and docked pose (blue) of the CREBBP bromodomain (shown in grey) in complex with compound I (PDB code 4TS8). The conserved Tyr1125 and Asn1168 residues, together with Arg1173 (a characteristic residue for the CREBBP

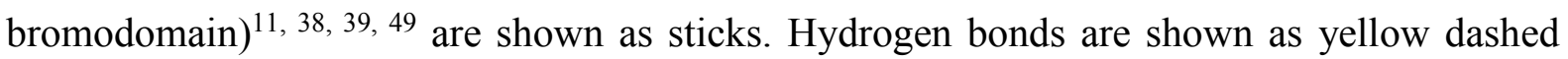
lines and the crystallographic water molecules are represented by red spheres. 


\section{Assessing the affinity difference between indolizine and indole ligands}

GSK2801 is reported to be a potent ligand for the BAZ2B bromodomain with a $\mathrm{K}_{\mathrm{d}}$ of 136 $n M{ }^{41}$ To study the influence on the binding affinity of the position of the nitrogen atom in our hit compound I, we decided to synthesize the indole analogue of indolizine GSK2801. Commercially available $1 H$-indol-5-ol (1) was transformed into compound $\mathbf{3}$ via alkylation of the phenol moiety with 1-iodopropane, followed by introduction of an $\mathrm{N}$-benzenesulfonyl group and bromination at C3 in presence of molecular bromine (Scheme 1). Bromo indole 3 was then coupled to (2-(methylsulfonyl)phenyl)boronic acid affording compound $\mathbf{4}$ in moderate yield. Removal of the sulfonyl group under basic conditions preceded the incorporation of the acetyl group to give the indole analogue of GSK2801 (5).

\section{Scheme $1^{\mathrm{a}}$}

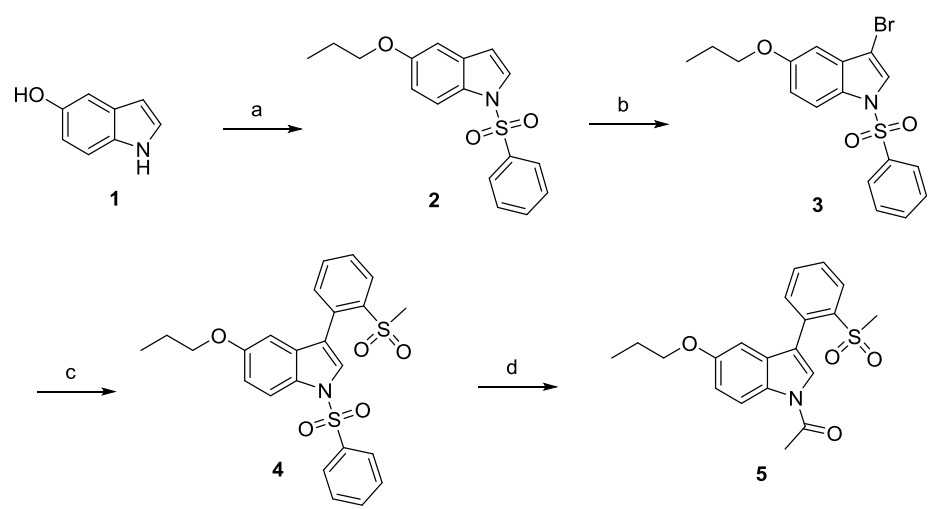

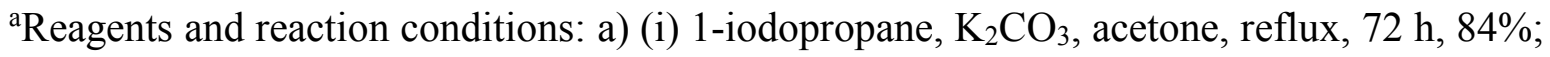
(ii) Benzenesulfonyl chloride, TBAB, $50 \% \mathrm{NaOH}, \mathrm{H}_{2} \mathrm{O}$, toluene, $0-25{ }^{\circ} \mathrm{C}, 69 \mathrm{~h}, 97 \%$; b) $\mathrm{Br}_{2}$,

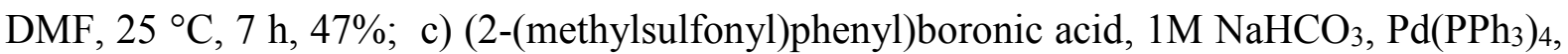
DME, $25-85^{\circ} \mathrm{C}, 15 \mathrm{~min}, 33 \%$; d) (i) $2 \mathrm{M} \mathrm{NaOH}, \mathrm{MeOH}, 85^{\circ} \mathrm{C}, 5 \mathrm{~h}, 69 \%$; (ii) $\mathrm{AcCl}, \mathrm{NaOH}$, TBAHS, DCM, $25{ }^{\circ} \mathrm{C}, 13 \mathrm{~h}, 63 \%$. TBAB: tetra- $n$-butylammonium bromide; DMF: dimethyl formamide; DME: 1,2-dimethoxyethane; TBAHS: tetrabutylammonium hydrogen sulfate. 
Interestingly, a 24 fold reduction of binding affinity towards BAZ2B was observed for acetyl indole 5 with respect to GSK2801 ( $\mathrm{IC}_{50}$ values of $8.55 \mu \mathrm{M}$ and $0.36 \mu \mathrm{M}$, respectively, determined by AlphaScreen, see Supporting Information) which indicates that the position of the nitrogen atom in the double-ring system is crucial.

\section{Synthesis}

We decided to focus our derivatization campaign on compounds $\mathbf{I}$ and VI as ligands. Compound I was selected because of its ligand efficiency for CREBBP $(0.34 \mathrm{kcal} / \mathrm{mol}$ per heavy atom) and the availability of the crystal structure (Figure 3), while compound VI was chosen because of its selectivity towards BAZ2B (Figure 2).

\section{Synthesis of compound I and derivatives}

The synthesis of the CREBBP hit $\mathbf{I}$ is shown in Scheme 2. The carboxylic acid of commercially available 2-(1H-indol-3-yl)acetic acid (6) was transformed into the corresponding methyl ester. Acetylation of the $\mathrm{N}$ atom afforded indole 7. Deprotonation of 7 in the presence of in situ generated LDA followed by reaction with acetic anhydride or 4methoxyphenylacetic anhydride delivered intermediates 8 and 9 respectively. Cyclization in the presence of hydrazine hydrate afforded the hit compound $\mathbf{I}$ and derivative $\mathbf{1 0}$ in moderate yields (Scheme 2).

\section{Scheme $2^{\mathrm{a}}$}

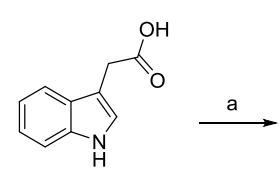

6
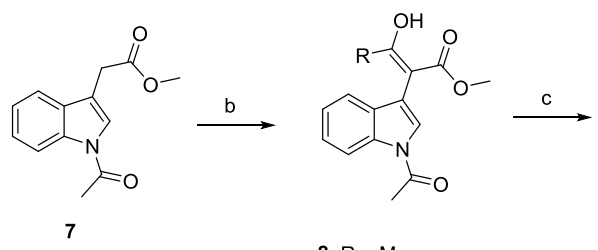

8: $\mathrm{R}=\mathrm{Me}$

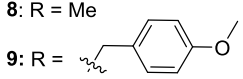

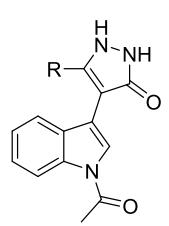

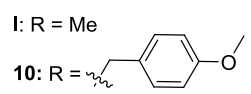


${ }^{a}$ Reagents and reaction conditions: a) (i) $\mathrm{MeOH}, \mathrm{H}_{2} \mathrm{SO}_{4}, 25{ }^{\circ} \mathrm{C}, 1 \mathrm{~h}, 94 \%$; (ii) $\mathrm{Ac}_{2} \mathrm{O}$, DMAP, Et 3 N, $25{ }^{\circ} \mathrm{C}, 17 \mathrm{~h}, 90 \%$; b) $\left({ }^{\mathrm{i}} \mathrm{Pr}\right)_{2} \mathrm{NH}, \mathrm{n}-\mathrm{BuLi}, \mathrm{THF},-75{ }^{\circ} \mathrm{C}, 1 \mathrm{~h}$, then, acetic anhydride or 4-methoxyphenylacetic anhydride, $-78{ }^{\circ} \mathrm{C}, 4 \mathrm{~h}$; c) Hydrazine hydrate, camphoric acid, EtOH, toluene, $93{ }^{\circ} \mathrm{C}, 30 \mathrm{~min}-1 \mathrm{~h}, 29-51 \%$ over two steps. DMAP: 4dimethylaminopyridine.

Hit compound I was then reacted with a variety of acid and sulfonyl chlorides affording disubstituted (11-18) as well as mono-substituted dihydro-pyrazole derivatives (19-22) as indicated in Scheme 3. Two more derivatives were prepared: upon condensation of 1,2dibromoethane with compound $\mathbf{I}$ in the presence of $\mathrm{K}_{2} \mathrm{CO}_{3}$ derivative $\mathbf{2 3}$ was obtained. The reaction of I with $p$-methoxybenzyl bromide in the presence of $\mathrm{NaH}$ afforded $\mathrm{O}$-alkylated product 24 (Scheme 3).

\section{Scheme $3^{\mathrm{a}}$}

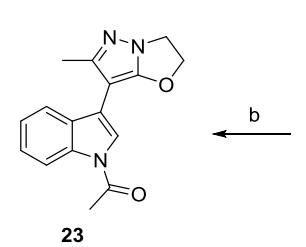

23

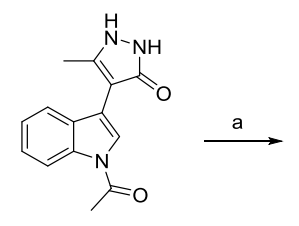

I

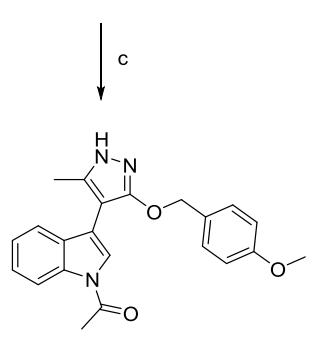

24

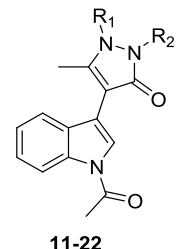

11-22

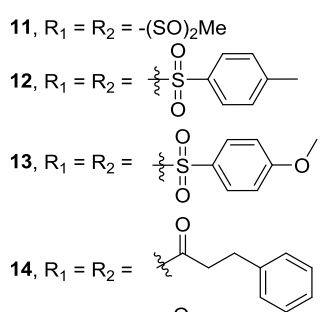

$15, R_{1}=R_{2}=$

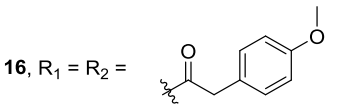

$17, \mathrm{R}_{1}=\mathrm{R}_{2}=$
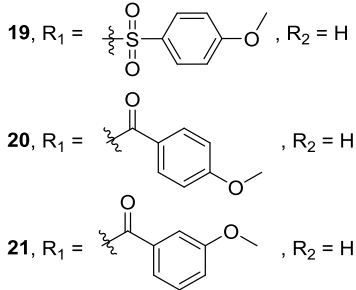

22, $R_{1}=$ 宸

${ }^{a}$ Reagents and reaction conditions: a) R-Cl, Et 3 N, DCM, $0-25{ }^{\circ} \mathrm{C}, 5-12 \mathrm{~h}, 24-89 \%$; b) 1,2dibromoethane, $\mathrm{K}_{2} \mathrm{CO}_{3}, \mathrm{DMF}, 80{ }^{\circ} \mathrm{C}, 7 \mathrm{~h}, 41 \%$; c) PMB-Br, NaH, TBAI, DMF, 0-25 ${ }^{\circ} \mathrm{C}$, 
1.5 h, 23 \%. PMB: 4-Methoxybenzyl ether; DMF: dimethyl formamide; TBAI: tetrabutylammonium iodide.

Finally, we decided to incorporate the propoxy group at position 5 of the indole, for which a similar protocol was applied to $1 H$-indol-5-ol (1) delivering the final products 27 and 28 (Scheme 4).

\section{Scheme $4^{\mathrm{a}}$}

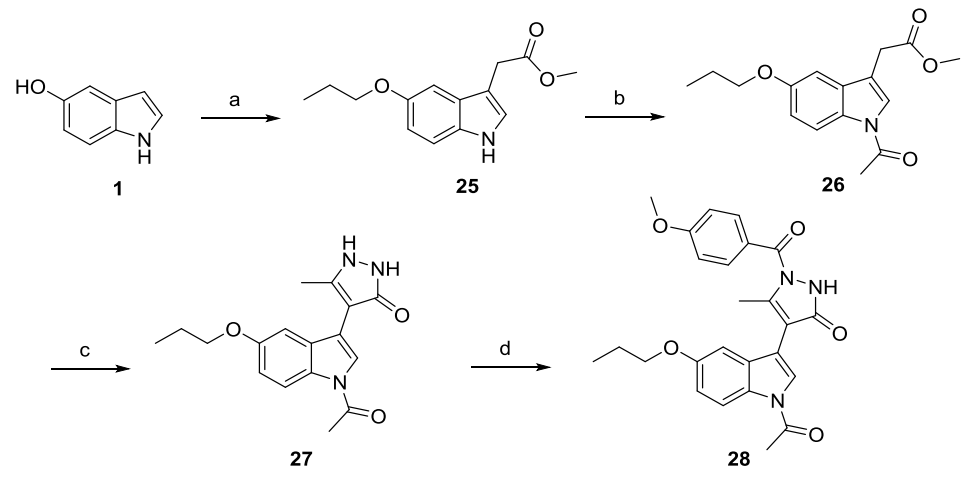

${ }^{\text {a}}$ Reagents and reaction conditions: a) (i) 1-iodopropane, $\mathrm{K}_{2} \mathrm{CO}_{3}$, acetone, reflux, $72 \mathrm{~h}, 84 \%$; (ii) $(\mathrm{COCl})_{2}, \mathrm{Et}_{2} \mathrm{O}, 0{ }^{\circ} \mathrm{C}$, then $\mathrm{NaOMe}$ in $\mathrm{MeOH},-78{ }^{\circ} \mathrm{C}, 3 \mathrm{~h}$; (iii) $\mathrm{Pd} / \mathrm{C}, \mathrm{NaH}_{2} \mathrm{PO}_{2}$, dioxane, $\mathrm{H}_{2} \mathrm{O}, 25{ }^{\circ} \mathrm{C}, 12 \mathrm{~h}, 88 \%$ over two steps; b) $\mathrm{Ac}_{2} \mathrm{O}$, DMAP, Et $3 \mathrm{~N}, \mathrm{THF}, 25{ }^{\circ} \mathrm{C}, 12 \mathrm{~h}, 42 \%$; c) (i) $\left({ }^{\mathrm{i}} \mathrm{Pr}\right)_{2} \mathrm{NH}, \mathrm{n}-\mathrm{BuLi}, \mathrm{THF},-78{ }^{\circ} \mathrm{C}, 1 \mathrm{~h}$, then, acetic anhydride, $-78{ }^{\circ} \mathrm{C}, 4 \mathrm{~h}$; (ii) Hydrazine hydrate, camphoric acid, EtOH, toluene, reflux, 4 h, $18 \%$; d) 4-Methoxybenzoyl chloride, $\mathrm{Et}_{3} \mathrm{~N}, \mathrm{DCM}, 0-25{ }^{\circ} \mathrm{C}, 12 \mathrm{~h}, 19 \%$.

\section{Synthesis of derivatives of compound VI}

The common intermediate for the synthesis of derivatives of ligand VI was obtained from the commercially available non-natural amino acid $\mathbf{2 9}$ in four steps with a $20 \%$ overall yield (Scheme 5). Condensation of intermediate 32 with diverse commercially available anilines afforded acetyl indole intermediates 33-38, which were then acylated in the presence of diverse acid chlorides affording compounds 39-46. Four additional derivatives were prepared 
by cleaving the methoxy subtituent in the presence of $\mathrm{BBr}_{3}$ to obtain phenol derivatives 47-50 (Scheme 5).

\section{Scheme $5^{\mathrm{a}}$}
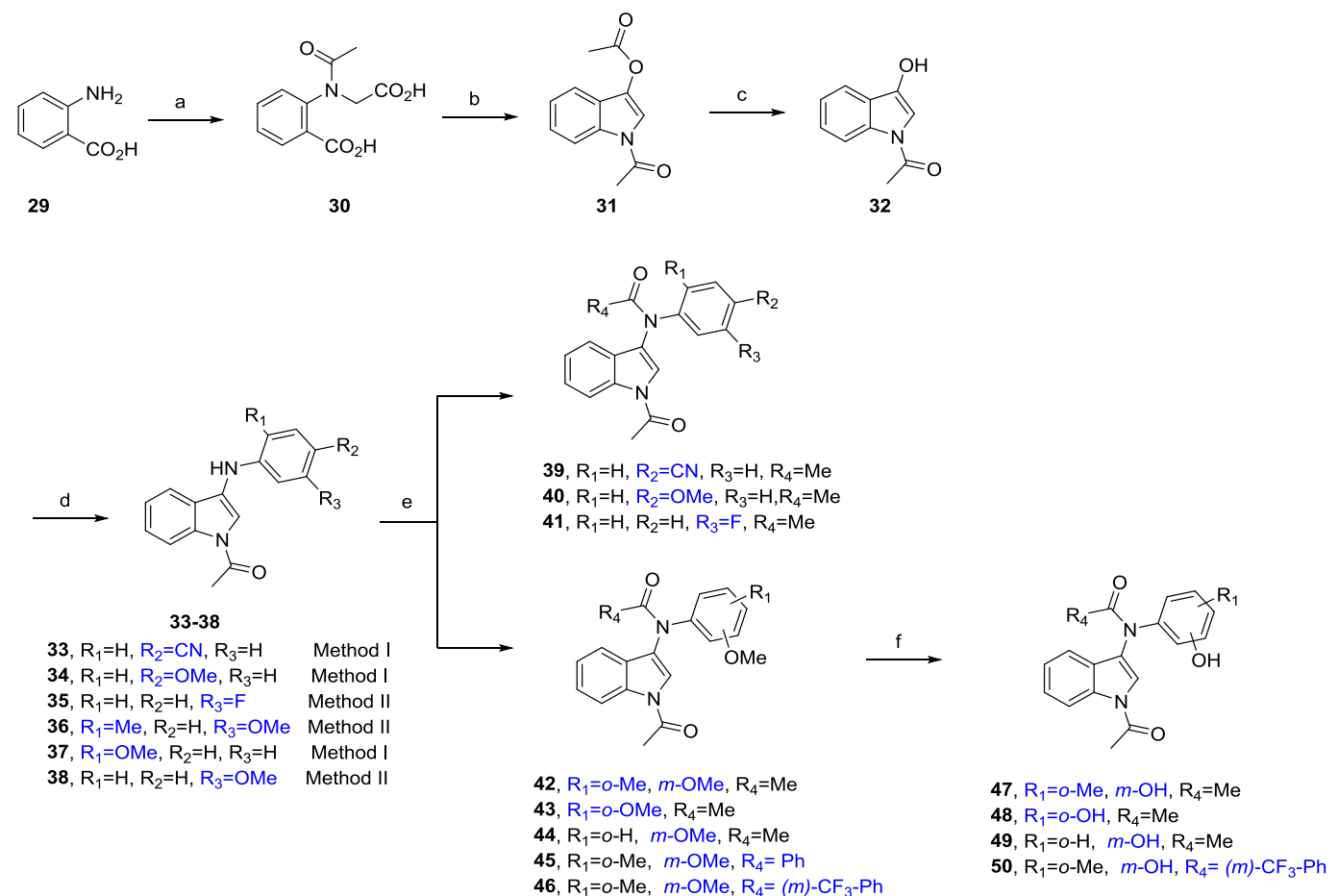

${ }^{a}$ Reagents and reaction conditions: a) (i) Chloroacetic acid, $\mathrm{K}_{2} \mathrm{CO}_{3}, \mathrm{H}_{2} \mathrm{O}, 90{ }^{\circ} \mathrm{C}, 16 \mathrm{~h}$; (ii) $\mathrm{Ac}_{2} \mathrm{O}, 25{ }^{\circ} \mathrm{C}, 30 \mathrm{~min}$, then $37 \% \mathrm{HCl}$ for $12 \mathrm{~h}, 33 \%$ over two steps; b) $\mathrm{Ac}_{2} \mathrm{O}, \mathrm{Et}_{3} \mathrm{~N}$, reflux, 30 min, $89 \%$; c) $\mathrm{Na}_{2} \mathrm{SO}_{3}$, reflux, 2 h, $83 \%$; d) Method I: Aniline, AcOH, reflux, 1-8 h, 26-56\%. Method II: aniline, pTSA, toluene, reflux, 2.5-4 h, 50-52\%; e) For MeCOCl, toluene, reflux, $6 \mathrm{~h}, 13-78 \%$; if $\mathrm{R}_{4}=$ aryl, $\mathrm{R}_{4} \mathrm{COCl}$, toluene, $\mathrm{Et}_{3} \mathrm{~N}$, DMAP, $100{ }^{\circ} \mathrm{C}, 1 \mathrm{~h}, 13-21 \%$; f) $\mathrm{BBr}_{3}$, DCM, $\quad 0-25 \quad{ }^{\circ} \mathrm{C}, \quad 1-12$ h, 47-84\%. pTSA: $p$-toluenesulfonic acid; DMAP: 4dimethylaminopyridine. 


\section{Biophysical Characterization}

\section{Compound I and derivatives}

Compound I was screened against a panel of ten different bromodomains using a thermal shift assay (Table 1). This initial screening revealed BRD9 bromodomain as a potential off target for compound $\mathbf{I}$ with a shift in the melting temperature of $1.3{ }^{\circ} \mathrm{C}$, which translated into a $\mathrm{K}_{\mathrm{D}}$ of $5.3 \mu \mathrm{M}$, as measured by a competition binding assay, ${ }^{55,56}$ and a ligand efficiency (LE) value of $0.38 \mathrm{kcal} / \mathrm{mol}$ per heavy atom. This result is in line with the recent work of Brennan and co-workers, who developed BRD7 and BRD9 nanomolar potent indolizine derivatives starting from the BAZ2B inhibitor GSK2801. ${ }^{22}$ Importantly, no activity of compound I was observed for the tested BET family members, BRD4(1) and BRD4(2).

Due to the involvement of the acetyl group of compound $\mathbf{I}$ in hydrogen bonds with the conserved Asn1168 and Tyr1125 residues of CREBBP (Figure 3), we decided to maintain this moiety and introduce the main modifications at the dihydro-pyrazole ring in order to gain affinity towards CREBBP.

On the outset, we decided to modulate the interactions of the solvent exposed $\mathrm{NH}$ groups of the dihydro-pyrazole ring. To do so, mono- and di-substituted amide and sulfonamides that could establish new interactions with the surrounding aminoacid residues including the characteristic Leu1109 and Arg1173 residues in the CREBBP bromodomain and His42 and Phe44 in BRD9 were incorporated (compounds 11-22, Table 1). The presence of methyl substituted sulfonamides in compound $\mathbf{1 1}$ provided a $\mathrm{K}_{\mathrm{D}}$ of $6.6 \mu \mathrm{M}$ in CREBBP, which is a three-fold binding affinity improvement with respect to the hit compound $\mathbf{I}$ and corresponds to a $\mathrm{LE}$ value of $0.26 \mathrm{kcal} / \mathrm{mol}$ per heavy atom.

In an effort to form $\pi$-stacking interactions with $\operatorname{Arg} 1173$ in CREBBP, ${ }^{11,38}$ and residues Phe43 and Phe44 in BRD9, aromatic substituents, some of them electron-rich, were 
incorporated (compounds 14-18 and 20-21). Compound 14 yielded the most active ligand towards BRD9 with a $\mathrm{K}_{\mathrm{D}}$ of $3.5 \mu \mathrm{M}$. Interestingly, the presence of a $p$-methoxybenzoate substituent in compound $\mathbf{2 0}$ resulted in a 2 -fold improvement of binding affinity with a thermal shift of $3.3{ }^{\circ} \mathrm{C}$ in CREBBP and a $\mathrm{K}_{\mathrm{D}}$ of $9.3 \mu \mathrm{M}$. At the same time, compound 20 retained the activity towards BRD9 with a thermal shift of $5.1{ }^{\circ} \mathrm{C}$ and a $\mathrm{K}_{\mathrm{D}}$ of $6.3 \mu \mathrm{M}$. The presence of a morpholine ring at the same position (derivative 22) could only slightly improve the binding affinity towards CREBBP with a $\mathrm{K}_{\mathrm{D}}$ of $12 \mu \mathrm{M}$.

A dihydropyrazolo-oxazole ring was installed (compound 23), which allowed us to revert the hydrogen bond donor capacity of the dihydro-pyrazole ring bearing two $\mathrm{NH}$ groups to a hydrogen bond acceptor fused ring. Remarkably, compound 23 showed a $K_{D}$ of $6.2 \mu \mathrm{M}$ in CREBBP and retained the LE of the initial hit $(0.34 \mathrm{kcal} / \mathrm{mol}$ per heavy atom $)$, which makes it an attractive lead for further optimization. On the other hand, compound $\mathbf{2 4}$ exhibited a drop in the thermal shift, probably due to steric clashes of the $p$-methoxybenzyl group.

We then aimed at establishing new interactions with the hydrophobic residues located on top of the binding site, Ile1122 and Leu1120 in CREBBP and Ala54 and Ile53 in BRD9, by substitution of the indole moiety at the 5 position with a propoxy group (Table 1, compounds 27 and 28), a modification proven to be successful in our previous work and in GSK2801.39, ${ }^{41}$ Unfortunately, the presence of the propoxy substituent retained the activity of $c a .10 \mu \mathrm{M}$. 
Table 1. Evaluation of compounds 10-24, 27, 28 derived from I.

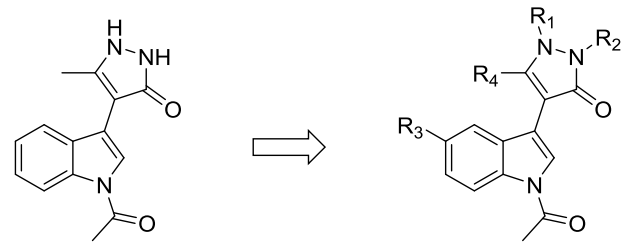

\begin{tabular}{|c|c|c|c|c|c|c|c|c|c|c|}
\hline \multirow{3}{*}{ Cmpd } & \multirow{3}{*}{$\mathrm{R}_{1}$} & \multirow{3}{*}{$\mathrm{R}_{2}$} & & \multirow{3}{*}{$\mathrm{R}_{4}$} & \multirow{2}{*}{\multicolumn{4}{|c|}{$\frac{10-24,27,28}{\Delta T_{m}\left({ }^{\circ} \mathrm{C}\right)^{[\mathrm{a}]}}$}} & \multirow{2}{*}{\multicolumn{2}{|c|}{$\mathrm{K}_{\mathrm{d}}(\mu \mathrm{M})^{[\mathrm{b}]}$}} \\
\hline & & & \multirow{2}{*}{$\mathrm{R}_{3}$} & & & & & & & \\
\hline & & & & & CBP & EP300 & BRD9 & BRD4(1) & CBP & BRD9 \\
\hline I & $\mathrm{H}$ & $\mathrm{H}$ & $\mathrm{H}$ & $\mathrm{Me}$ & $\begin{array}{c}0.3 \\
(0.1)\end{array}$ & $\begin{array}{c}0.4 \\
(0.1)\end{array}$ & $\begin{array}{c}1.3 \\
(0.1)\end{array}$ & $\begin{array}{l}-0.1 \\
(0.1)\end{array}$ & 20.0 & 5.3 \\
\hline 10 & $\mathrm{H}$ & $\mathrm{H}$ & $\mathrm{H}$ & & $\begin{array}{l}-0.1 \\
(0.2)\end{array}$ & $\begin{array}{l}-0.6 \\
(0.2)\end{array}$ & $\begin{array}{l}-0.8 \\
(0.7)\end{array}$ & $\begin{array}{l}-0.9 \\
(0.4)\end{array}$ & - & - \\
\hline 11 & $-\mathrm{SO}_{2} \mathrm{Me}$ & $-\mathrm{SO}_{2} \mathrm{Me}$ & $\mathrm{H}$ & $\mathrm{Me}$ & $\begin{array}{c}2.2 \\
(0.2)\end{array}$ & $\begin{array}{c}2.7 \\
(0.1)\end{array}$ & $\begin{array}{l}1.0 \\
(0.8)\end{array}$ & $\begin{array}{c}0.6 \\
(0.5)\end{array}$ & 6.6 & \\
\hline 12 & & & $\mathrm{H}$ & $\mathrm{Me}$ & $\begin{array}{c}1.4 \\
(0.5)\end{array}$ & $\begin{array}{l}-0.7 \\
(0.7)\end{array}$ & $\begin{array}{l}-0.5 \\
(0.3)\end{array}$ & $\begin{array}{l}-0.4 \\
(0.5)\end{array}$ & - & - \\
\hline 13 & & & $\mathrm{H}$ & $\mathrm{Me}$ & $\begin{array}{c}1.5 \\
(0.4)\end{array}$ & $\begin{array}{c}0.0 \\
(0.2)\end{array}$ & $\begin{array}{l}-1.0 \\
(0.7)\end{array}$ & $\begin{array}{c}0.0 \\
(0.3)\end{array}$ & - & - \\
\hline 14 & & & $\mathrm{H}$ & $\mathrm{Me}$ & $\begin{array}{c}2.8 \\
(0.7)\end{array}$ & $\begin{array}{c}1.0 \\
(0.3)\end{array}$ & $\begin{array}{c}2.8 \\
(1.6)\end{array}$ & $\begin{array}{c}1.2 \\
(0.5)\end{array}$ & 17 & 3.5 \\
\hline 15 & & & $\mathrm{H}$ & $\mathrm{Me}$ & $\begin{array}{l}-0.6 \\
(0.1)\end{array}$ & $\begin{array}{l}-0.3 \\
(0.1)\end{array}$ & $\begin{array}{c}0.2 \\
(0.2)\end{array}$ & $\begin{array}{l}-0.3 \\
(0.1)\end{array}$ & - & - \\
\hline 16 & & & $\mathrm{H}$ & $\mathrm{Me}$ & $\begin{array}{l}-0.9 \\
(0.1)\end{array}$ & $\begin{array}{l}-0.3 \\
(0.1)\end{array}$ & $\begin{array}{c}0.3 \\
(0.3)\end{array}$ & $\begin{array}{c}0.1 \\
(0.2)\end{array}$ & - & - \\
\hline 17 & & & $\mathrm{H}$ & $\mathrm{Me}$ & $\begin{array}{l}-0.2 \\
(0.7)\end{array}$ & $\begin{array}{c}0.0 \\
(0.2)\end{array}$ & $\begin{array}{l}-0.5 \\
(0.7)\end{array}$ & $\begin{array}{l}-0.9 \\
(0.3)\end{array}$ & - & - \\
\hline 18 & & & $\mathrm{H}$ & $\mathrm{Me}$ & $\begin{array}{l}-0.5 \\
(0.6)\end{array}$ & $\begin{array}{c}0.0 \\
(0.1)\end{array}$ & - & $\begin{array}{l}-2.3 \\
(0.5)\end{array}$ & - & - \\
\hline 19 & & $\mathrm{H}$ & $\mathrm{H}$ & $\mathrm{Me}$ & $\begin{array}{l}-0.4 \\
(0.2)\end{array}$ & $\begin{array}{l}-0.4 \\
(0.2)\end{array}$ & $\begin{array}{c}0.8 \\
(0.5)\end{array}$ & $\begin{array}{l}-1.6 \\
(0.3)\end{array}$ & - & - \\
\hline 20 & & $\mathrm{H}$ & $\mathrm{H}$ & $\mathrm{Me}$ & $\begin{array}{c}3.3 \\
(0.7)\end{array}$ & $\begin{array}{c}5.3 \\
(0.9)\end{array}$ & $\begin{array}{c}5.1 \\
(1.5)\end{array}$ & $\begin{array}{c}0.2 \\
(0.7)\end{array}$ & 9.3 & 6.3 \\
\hline 21 & & $\mathrm{H}$ & $\mathrm{H}$ & $\mathrm{Me}$ & $\begin{array}{c}-0.6 \\
(0.8)\end{array}$ & $\begin{array}{c}1.0 \\
(0.7)\end{array}$ & - & $\begin{array}{l}-0.5 \\
(0.4)\end{array}$ & - & - \\
\hline 22 & & $\mathrm{H}$ & $\mathrm{H}$ & $\mathrm{Me}$ & $\begin{array}{c}1.4 \\
(0.3)\end{array}$ & $\begin{array}{c}2.5 \\
(0.1)\end{array}$ & $\begin{array}{l}-0.6 \\
(0.7)\end{array}$ & $\begin{array}{c}0.6 \\
(0.3)\end{array}$ & 12 & - \\
\hline 23 & & & & & $\begin{array}{l}3.5 \\
(0.2)\end{array}$ & $\begin{array}{c}2.2 \\
(0.4)\end{array}$ & $\begin{array}{l}1.8 \\
(1.0)\end{array}$ & $\begin{array}{l}1.5 \\
(0.4)\end{array}$ & 6.2 & - \\
\hline
\end{tabular}




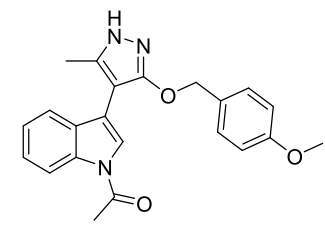

27

$\mathrm{H} \quad \mathrm{H}$

$\mathrm{OPr} \quad \mathrm{Me}$

$\begin{array}{lll}0.1 & 0.0 & 0.3\end{array}$

$(0.1) \quad(0.1) \quad(0.3)$

$27 \mathrm{H}$

$\begin{array}{lll}0.4 & 0.4 & 0.7\end{array}$

0.5

$(0.2) \quad(0.1)$

(0.1)

28<smiles>[Y]C(=O)c1ccc(OC)cc1</smiles>

$\mathrm{H} \quad \mathrm{OPr} \quad \mathrm{Me}$

\section{$9.8>50$}

${ }^{\text {[a] }}$ Median value of the shift in the melting temperature. The total number of measurements for each compound and bromodomain was between 7 and 24. Ligand and protein concentrations were $100 \mu \mathrm{M}$ and $2 \mu \mathrm{M}$, respectively. SEM values are given in parenthesis. The similar thermal shift values measured with the CREBBP bromodomain and its paralogue, EP300, are consistent with the fact that identical residues are present in the acetyl-lysine binding site of both proteins. ${ }^{[b]} \mathrm{K}_{d}$ values were determined by a competition binding assay ${ }^{55}$, 56 in duplicates. Dose-response data and fitting curves can be found in the Supporting Information. Dashes indicate data not acquired.

Importantly, with the exception of compounds 14 and $\mathbf{2 3}$, all derivatives displayed $\Delta \mathrm{T}_{\mathrm{m}}$ values of less than $0.6{ }^{\circ} \mathrm{C}$ for BRD4(1), one of the most promiscuous bromodomains. ${ }^{11,38,57}$

\section{Compound VI and derivatives}

Intrigued by the selectivity difference observed in the hit compound VI towards BAZ2B

(Figure 2), we decided to examine its binding mode more closely. As we could not obtain crystals of the complex of compound VI with BAZ2B, several analogues were synthesized (Table 2) aiming not only to obtain a crystal structure of the complex but also to improve the binding affinity towards BAZ2B. The chloroacetamide moiety was replaced by metabolically more stable amides in all derivatives to avoid covalent binding to the protein. 
Table 2. Evaluation of compounds 39-50 derived from VI.

\begin{tabular}{|c|c|c|c|c|c|c|}
\hline & & & vi & & $39-50$ & \\
\hline Cmpd & $\mathrm{R}_{1}$ & $\mathrm{R}_{2}$ & $\mathrm{R}_{3}$ & $\mathrm{R}_{4}$ & $\begin{array}{c}\mathrm{K}_{\mathrm{d}}(\mu \mathrm{M})^{[\mathrm{a}]} \\
\text { BAZ2B }\end{array}$ & $\% \mathrm{Ctrl} B A Z 2 \mathrm{~B}^{[\mathrm{b}]}$ \\
\hline VI & $\mathrm{H}$ & $\mathrm{H}$ & $\mathrm{H}$ & & $>50$ & 91.3 \\
\hline 39 & $\mathrm{H}$ & $\mathrm{CN}$ & $\mathrm{H}$ & Acetyl & - & 99.7 \\
\hline 40 & $\mathrm{H}$ & $\mathrm{OMe}$ & $\mathrm{H}$ & Acetyl & - & 73.5 \\
\hline 41 & $\mathrm{H}$ & $\mathrm{H}$ & $\mathrm{F}$ & Acetyl & - & 91.4 \\
\hline 42 & $\mathrm{Me}$ & $\mathrm{H}$ & $\mathrm{OMe}$ & Acetyl & - & 71.9 \\
\hline 43 & $\mathrm{OMe}$ & $\mathrm{H}$ & $\mathrm{H}$ & Acetyl & - & 86.3 \\
\hline 44 & $\mathrm{H}$ & $\mathrm{H}$ & $\mathrm{OMe}$ & Acetyl & - & 89.6 \\
\hline 45 & $\mathrm{Me}$ & $\mathrm{H}$ & $\mathrm{OMe}$ & & - & 77.5 \\
\hline 46 & $\mathrm{Me}$ & $\mathrm{H}$ & $\mathrm{OMe}$ & & 140 & 87.3 \\
\hline 47 & $\mathrm{Me}$ & $\mathrm{H}$ & $\mathrm{OH}$ & Acetyl & 23 & 54.2 \\
\hline 48 & $\mathrm{OH}$ & $\mathrm{H}$ & $\mathrm{H}$ & Acetyl & - & 88.4 \\
\hline 49 & $\mathrm{H}$ & $\mathrm{H}$ & $\mathrm{OH}$ & Acetyl & - & 86.3 \\
\hline 50 & $\mathrm{Me}$ & $\mathrm{H}$ & $\mathrm{OH}$ & & 39 & $\begin{array}{c}29.8 \\
\left(\mathrm{IC}_{50}=27 \mu \mathrm{M}\right)\end{array}$ \\
\hline
\end{tabular}

[a] $\mathrm{K}_{d}$ values were determined by a competition binding assay ${ }^{55,56}$ in duplicates. Doseresponse data and fitting curves are in the Suppl. Inform. ${ }^{[b]}$ Percentage of the measured signal (i.e., percentage binding of acetylated histone peptide to BAZ2B) relative to the negative control at a compound concentration of $50 \mu \mathrm{M}$. Lower values indicate stronger binding of the compounds. The AlphaScreen competition binding assay was performed at Reaction Biology. Dashes indicate data not acquired.

The affinity of the synthesized derivatives 39-50 against BAZ2B was assessed by an AlphaScreen competition binding assay at a compound concentration of $50 \mu \mathrm{M}$. Compound 
47, bearing an $o$-methyl and $m$-hydroxy substituent at the benzene ring, showed $54 \%$ reduction of signal relative to the negative control DMSO in the AlphaScreen binding assay, which translated into a $\mathrm{K}_{\mathrm{D}}$ of $23 \mu \mathrm{M}$ and a $\mathrm{LE}$ value of $0.27 \mathrm{kcal} / \mathrm{mol}$ per heavy atom. Upon substitution of the acetyl substituent at $\mathrm{R}_{4}$ by a $m-\mathrm{CF}_{3}$-phenyl group, an $\mathrm{IC}_{50}$ value of $27 \mu \mathrm{M}$ in the AlphaScreen assay and a $\mathrm{K}_{\mathrm{D}}$ of $39 \mu \mathrm{M}$ (BROMOscan) were measured for compound 50.

Crystal structures of the most potent derivatives, 47 and 50, in complex with BAZ2B were solved at $1.71 \AA$ and $1.78 \AA$ resolution, respectively. Compounds 47 and 50 (Figure 5A, B) have essentially identical binding mode in BAZ2B. Similarly to the binding mode of the hit I in CREBBP (Figure 3), the $N$-acetyl substituent of the indole moiety of compounds $\mathbf{4 7}$ and $\mathbf{5 0}$ is engaged in hydrogen bonds with the side chain of the conserved Tyr1901 and Asn1944, where the hydrogen bond with Tyr1901 is bridged by a water molecule. An additional hydrogen bond is formed between the carbonyl group of the acetamide and the backbone NH of Asn1894 in the ZA loop. The $o$-methyl substituent of the phenol ring provides sufficient steric hindrance to block the conformation of compounds $\mathbf{4 7}$ and $\mathbf{5 0}$ with their hydroxyphenyl ring pointing towards Trp1887, which is the first residue of the WPF segment in BAZ2B. The additional trifuoromethylbenzoate of compound $\mathbf{5 0}$ points towards the solvent (Figure 5B) which explains the similar affinity for BAZ2B of compounds $\mathbf{4 7}$ and $\mathbf{5 0}$ (Table 2).

As mentioned above, the bromodomains of BRD9 and BRPF1/3 belong to the same subfamily. Aiming to obtain further structural information, we took advantage of the availability in our laboratory of crystals of the apo state of the bromodomain of BRPF1b which were soaked in a solution of compound I. In this way, we solved the crystal structure of the complex of compound I with BRPF1b at a resolution of $1.35 \AA$ (PDB code 5D7X). Interestingly, the size of the so-called gatekeeper residue, small (Val1174 in CREBBP) and 
large (Phe714 in BRPF1b), has a noticeable influence on the orientation of the indole moiety (Figure 5C). Furthermore, the presence of the bulkier Phe714 residue in the BRPF1b bromodomain has a strong effect on the orientation of the dihydro-pyrazole ring which is rotated by about $180^{\circ}$ in BRPF1b with respect to the complex with CREBBP. Despite these structural differences compound I has very similar affinity for the bromodomains of CREBBP and BRPF1b with $\mathrm{K}_{d}$ values of $20 \mu \mathrm{M}$ and $15 \mu \mathrm{M}$, respectively (see Supporting Information).

The superposition of the X-ray structures of compound $\mathbf{I}$ in CREBBP and BRPF1b with compound 47 in BAZ2B provides additional evidence on the influence of the gatekeeper residue for ligand binding (Figure 5, D). Interestingly, the 6-membered-ring of the indole moiety of compound $\mathbf{4 7}$ is located between the indole of compound $\mathbf{I}$ in BRPF1b and CREBBP because the gatekeeper residue in BAZ2B (Ile1950) is smaller than the one in BRPF1b (Phe714) and bigger than that in CREBBP (Val1174). It is important to note that in these three crystal structures (viz., the complexes I/CREBBP, I/BRPF1b, and 47/BAZ2B) there are no crystal contacts in the binding site that could affect the orientation of the acetyl indole scaffold. Moreover, the structure of BAZ2B is essentially identical in the complex with compounds $\mathbf{4 7}$ and $\mathbf{5 0}$, and the same is observed for the structures of CREBBP in the complex with compound I and a previously reported acetyl benzene ligand (PDB code 4TQN) which differ only by a small rigid-body displacement of the ZA loop. It is also interesting to compare with the orientation of the scaffold of the BAZ2B inhibitor GSK2801. The same progressive tilting of the indole emerges from the structural superposition of the complex of BAZ2B and the nanomolar inhibitor GSK2801 (PDB code 4RVR) ${ }^{41}$ with the crystal structures of the hit compound $\mathbf{I}$ in CREBBP and BRPF1b (Figure 5, E). Overall, these structural data suggest that acetyl indole mimics the acetylated lysine side chain in its rather unselective binding to bromodomains. In addition, the precise orientation of the indole 
double-ring system and the substituent at its position 3 are influenced by the size of the gatekeeper residue which is different in different bromodomains. 
A)

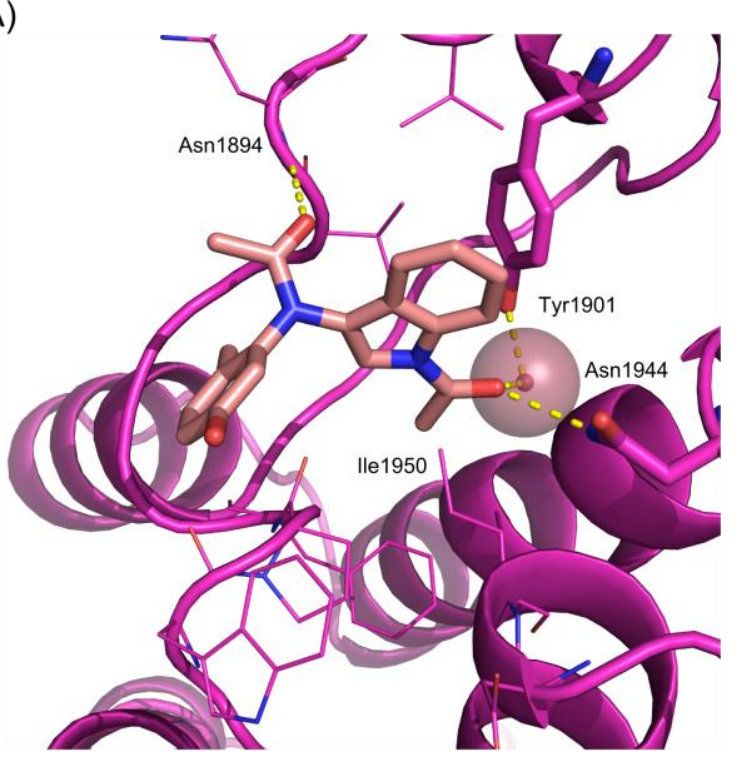

C)

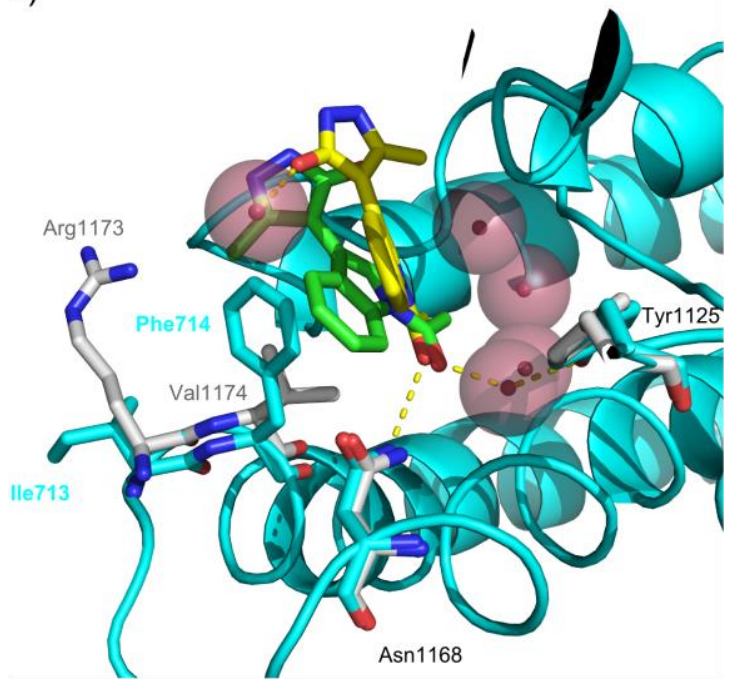

D)

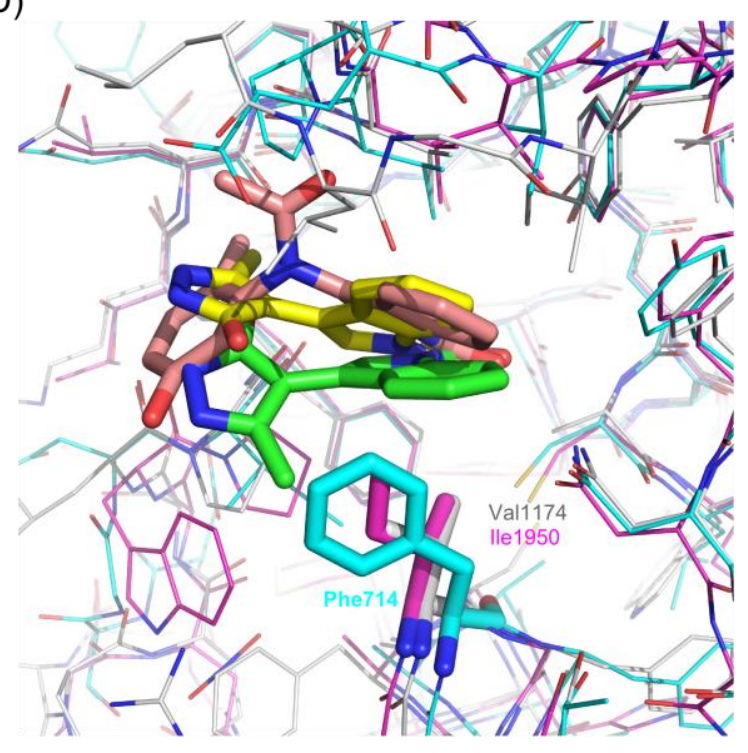

B)

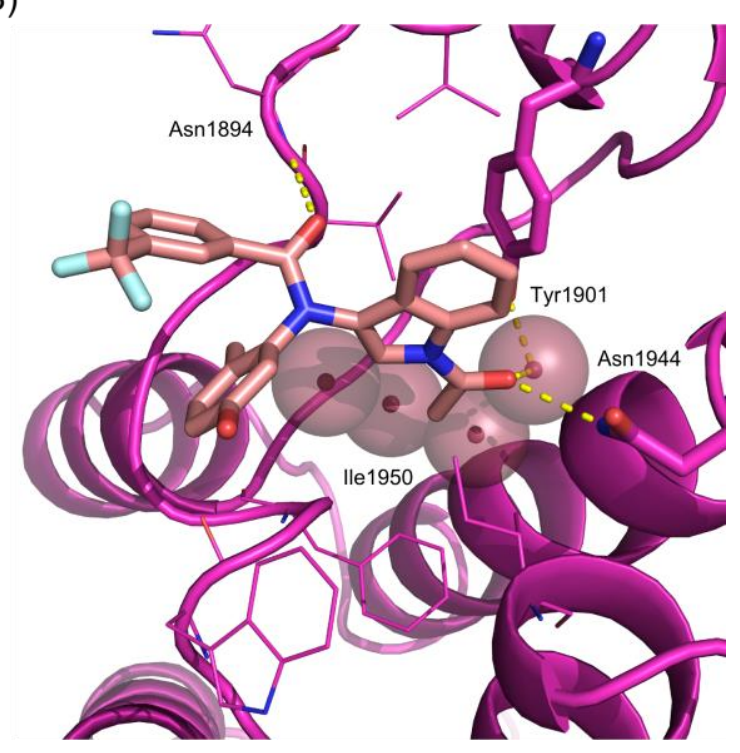

E)

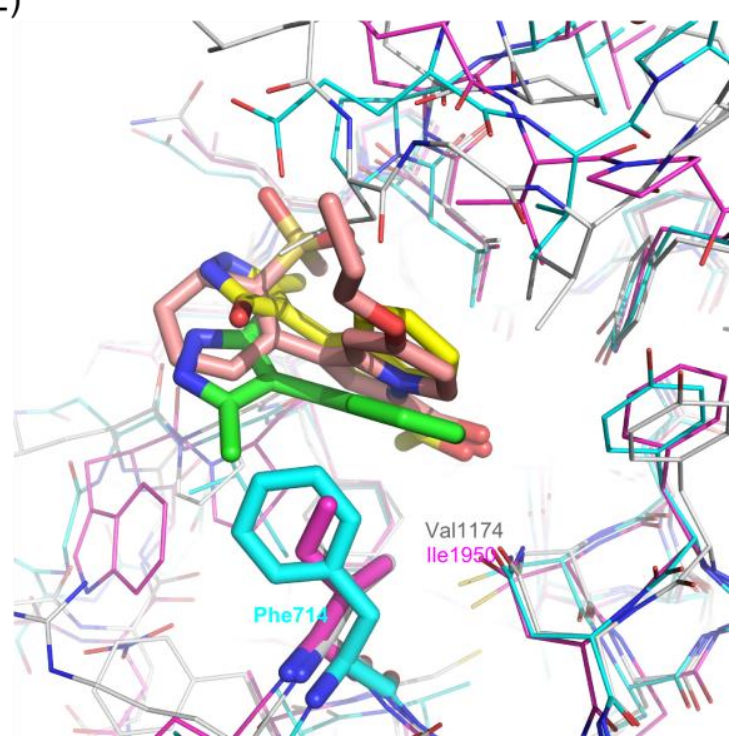


Figure 5. The crystal structures show the influence of the gatekeeper on the binding mode of the ligand. A) Crystal structures of the BAZ2B bromodomain in complex with compound 47 (PDB code 5E73). B) Same as A) for the complex with compound $\mathbf{5 0}$ (PDB code 5E74). C) Crystal structure of the complex of compound I (yellow) and the BRPF1b bromodomain (blue) (PDB code 5D7X) structurally superposed to the crystal structure with CREBBP (compound I shown in green and CREBBP side chains shown in grey). D) Superposition of the crystal structures of compound 47 (brown) in BAZ2B (pink) and compound I (green and yellow), in CREBBP (grey) and BRPF1b (blue), respectively. The side chain of the gatekeeper is shown in cylinders with labels for the residue number. E) Same as D) for the BAZ2B inhibitor GSK2801 (brown) (PDB code 4RVR). In all panels, hydrogen bonds are shown as yellow dashed lines and the crystallographic water molecules are represented by spheres.

\section{Conclusions}

We have discovered in silico a series of small molecule antagonists of the bromodomains of CREBBP and BAZ2B by docking about 200 compounds containing an acetyl indole moiety, which we had identified by scaffold hopping from a potent BAZ2B ligand. Considering that only 14 compounds were tested in vitro (by a competition binding assay), the hit rate of the in silico screening based on scaffold hopping and docking is $50 \%$ and $29 \%$ for CREBBP and BAZ2B, respectively. One of the original hits (compound I) has an equilibrium dissociation constant of $20 \mu \mathrm{M}, 15 \mu \mathrm{M}$, and $5.3 \mu \mathrm{M}$ for CREBBP, BRPF1b, and BRD9, respectively. With a relatively small derivatization campaign (i.e., ca. 30 derivatives) we were able to improve the affinity for CREBBP and BAZ2B, and maintain the ligand efficiency $(0.34 \mathrm{kcal} / \mathrm{mol}$ per heavy atom for both hit $\mathbf{I}$ and derivative $\mathbf{2 3}$ in CREBBP) or even slightly improve it (from $<0.26$ for hit VI to $0.27 \mathrm{kcal} / \mathrm{mol}$ per heavy atom for 
compound 47 in BAZ2B). The crystal structures of three acetyl indole derivatives in complex with three different bromodomains confirm the binding mode predicted by docking with the acetyl oxygen of the ligand involved as hydrogen bond acceptor in two hydrogen bonds with the conserved Asn side chain in the BC loop and a structural water that acts as bridge to the conserved Tyr of the ZA loop. Moreover, the X-ray structures show that the size of the gatekeeper side chain (Val1174, Ile1950, and Phe714 in the bromodomains of CREBBP, BAZ2B, and BRPF1b, respectively) influences the orientation of the indole moiety. This structural information can be used to further improve the selectivity for a single bromodomain target or a small subset of bromodomains sharing the same gatekeeper residue.

\section{MATERIALS AND METHODS}

Scaffold hopping. We have used an activity-oriented fingerprint that consists of 1) chemical features such as hybridization states and different types of hydrogen bonding donors and acceptors; 2) two-dimensional topology index as a way to reflect spatial arrangement of such features; and 3) three-dimensional shape descriptors (Figure S1 in the supporting information). A similarity coefficient is computed between two fingerprints ranging from 0 to 1, with 1 being the highest similarity, where the two molecules are not necessarily identical. As such, scaffold hopping resembles pharmacophore mapping, but distinguishes itself by using a molecular fingerprint.

Docking and scoring. The genetic algorithm-based program for flexible ligand docking has been described in previous applications. ${ }^{48,}$ 50-52 About 20 docking poses for each compound were first minimized by the CHARMM program ${ }^{58}$ and subsequently ranked by a transferable scoring function. ${ }^{45,50-54}$

Assays. Thermal shift measurements were carried out as previously described. ${ }^{39,49}$ Thermal shift assays detect, by a fluorescent dye, the increase in thermal stability of a protein in the 
presence of a ligand. ${ }^{59}$ BROMOscan technology is a competition experiment that uses an immobilized ligand and a DNA tagged bromodomain protein. ${ }^{55,56}$ Compounds that bind to the bromodomain of interest will prevent bromodomain binding to the immobilized ligand. The amount of bromodomain captured on the solid support is then quantified by qPCR and dissociation constants are calculated. AlphaScreen assays consist of a donor bead that is able to transfer singlet oxygen to an acceptor bead that is in close proximity, and as a result, the acceptor bead emits a lumininescent/fluorescent signal. In the presence of a bromodomain ligand, the donor-acceptor complex is disrupted leading to a loss of singlet oxygen transfer and loss of the fluorescent signal. Further details about the assays can be found in the Supporting Information.

X-ray crystallography. The His-tagged human bromodomains of CREBBP (residues 1081-1097), BRPF1b (residues 626-740), and BAZ2B (residues 1858-1972) were expressed in E.coli. The purification procedures are reported in the Supporting Information. The inhibitors were soaked into apo crystals of the bromodomains of BRPF1b and BAZ2B while the structure of the complex of compound I and CREBBP was obtained by co-crystallization as described in the Supporting Information. Data collection and refinement statistics are given in Table S1.

\section{ASSOCIATED CONTENT}

Supporting Information. General procedures for scaffold hopping, synthesis and characterization, biophysical and biological evaluation of final compounds, and X-ray crystal structure refinement data is available free of charge via the Internet at http://pubs.acs.org.

\section{Accession Codes}

The PDB accession codes for CREBBP and BRPF1b in complex with the hit compound $\mathbf{I}$ are 4TS8 and 5D7X, respectively. Coordinates and structure factors for the BAZ2B 
bromodomain in complex with compounds $\mathbf{4 7}$ and $\mathbf{5 0}$ have been deposited in the PDB with accession codes 5E73 and 5E74, respectively.

\section{AUTHOR INFORMATION}

\section{Corresponding Author}

*Amedeo Caflisch. E-mail: caflisch@bioc.uzh.ch.

* Cristina Nevado. E-mail: cristina.nevado@chem.uzh.ch.

\section{Funding Sources}

This work was supported by the Swiss Cancer Society (Krebsliga) and the Swiss National Science Foundation. We thank the Structural Genomics Consortium at Oxford University for providing the plasmids of all the bromodomains but EP300 (provided by AddGene).

\section{ACKNOWLEDGMENT}

We thank Dr. Emilie Frugier and Dr. Dimitrios Spiliotopous for interesting discussions and help with the thermal shift assay. We thank Lisa Caflisch, Ursina Suter, and Cecilia Ferdenzi for protein purification and Dr. Alvaro Salvador and Anna Coppola for their efforts towards the synthesis of the hit compound I. Nicholas Deerain is acknowledged for performing part of the thermal shift assays. We are grateful to the staff at PXI and PXIII beamlines, Swiss Light Source, Paul Scherrer Institute (Villigen, Switzerland) and at XDR1 beamline, ELETTRA Synchrotron Light Source (Trieste, Italy) for on-site assistance.

\section{ABBREVIATIONS}

BAZ2B, bromodomain adjacent to zinc finger domain, 2B ; BET, bromodomain and extra terminal domain; BRD2, 3, 4, 7, 9 bromodomain containing 2, 3, 4, 7, 9; BRD4(1), first/second bromodomain of BRD4; BRPF1b, bromodomain and PHD finger containing, 1; BRDT, bromodomain testis-specific protein; CBP, CREB binding protein; CREBBP, CREB 
binding protein; DMAP: 4-dimethylaminopyridine; DME: 1,2-dimethoxyethane; DMF: dimethyl formamide; DMSO, dimethyl sulfoxide; EP300, E1A binding protein p300; HAT, histone acetyl transferase; LE, ligand efficiency; NMC, NUT midline carcinoma; NUT, nuclear protein in testis; PHD, plant homeodomain; PMB, 4-methoxybenzyl ether; SMARCA4, SWI/SNF related, matrix associated, actin dependent regulator of chromatin, subfamily a, member 4; SWI/SNF, SWItch/Sucrose non-fermentable; TAF1(2), second bromodomain of TAF1, TATA box binding protein (TBP)-associated factor; TBAB: tetra-nbutylammonium bromide; TBAHS: tetrabutylammonium hydrogen sulfate; TBAI, tetrabutylammonium iodide.

\section{TOC and Sinopsis}

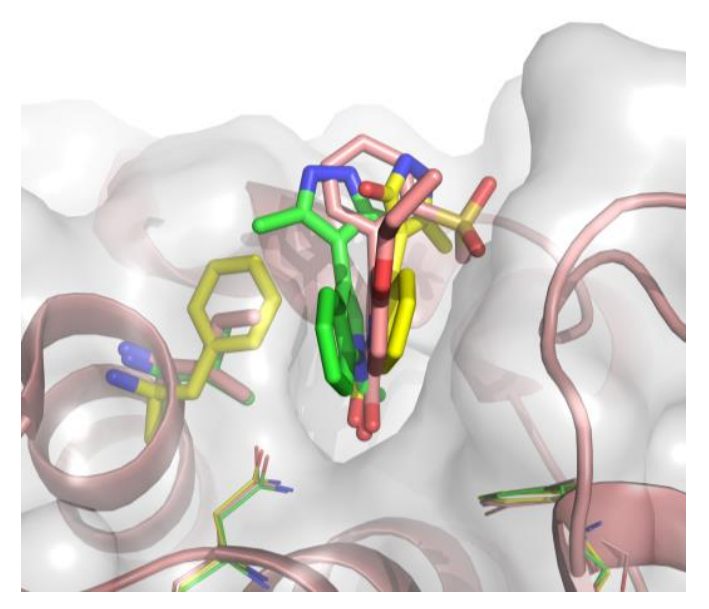

Ligand promiscuity as tool for structural analysis: The in silico discovery and chemical optimization of acetyl indoles as ligands of different human bromodomains are presented here. The crystal structures of acetyl indole derivatives in three different bromodomains show that the size of the gatekeeper residue influences the precise orientation of small-molecule ligands in the bromodomain binding site.

\section{REFERENCES}

1. Holliday, R. The Inheritance of Epigenetic Defects. Science 1987, 238, 163-170.

2. Kouzarides, T. Chromatin modifications and their function. Cell 2007, 128, 693-705. 
3. Flynn, E. M.; Huang, Oscar W.; Poy, F.; Oppikofer, M.; Bellon, Steve F.; Tang, Y.; Cochran, Andrea G. A Subset of Human Bromodomains Recognizes Butyryllysine and Crotonyllysine Histone Peptide Modifications. Structure 2015, 23, 1801-1814.

4. Prinjha, R. K.; Witherington, J.; Lee, K. Place your BETs: the therapeutic potential of bromodomains. Trends Pharmacol. Sci. 2012, 33, 146-153.

5. Müller, S.; Filippakopoulos, P.; Knapp, S. Bromodomains as therapeutic targets. Expert Rev. Mol. Med. 2011, 13, 1-21.

6. Hewings, D. S.; Rooney, T. P. C.; Jennings, L. E.; Hay, D. A.; Schofield, C. J.; Brennan, P. E.; Knapp, S.; Conway, S. J. Progress in the Development and Application of Small Molecule Inhibitors of Bromodomain-Acetyl-lysine Interactions. J. Med. Chem. 2012, 55, 9393-9413.

7. Filippakopoulos, P.; Knapp, S. Targeting bromodomains: epigenetic readers of lysine acetylation. Nat. Rev. Drug Discov. 2014, 13, 339-358.

8. Brand, M.; Measures, A. M.; Wilson, B. G.; Cortopassi, W. A.; Alexander, R.; Höss, M.; Hewings, D. S.; Rooney, T. P. C.; Paton, R. S.; Conway, S. J. Small Molecule Inhibitors of Bromodomain-Acetyl-lysine Interactions. ACS Chem. Biol. 2015, 10, 22-39.

9. $\quad$ www.clinicaltrials.gov, accessed on 18/10/2015.

10. Jennings, L. E.; Measures, A. R.; Wilson, B. G.; Conway, S. J. Phenotypic screening and fragment-based approaches to the discovery of small-molecule bromodomain ligands. Future Med. Chem. 2014, 6, 179-204.

11. Hay, D. A.; Fedorov, O.; Martin, S.; Singleton, D. C.; Tallant, C.; Wells, C.; Picaud, S.; Philpott, M.; Monteiro, O. P.; Rogers, C. M.; Conway, S. J.; Rooney, T. P. C.; Tumber, A.; Yapp, C.; Filippakopoulos, P.; Bunnage, M. E.; Müller, S.; Knapp, S.; Schofield, C. J.; Brennan, P. E. Discovery and Optimization of Small-Molecule Ligands for the CBP/p300 Bromodomains. J. Am. Chem. Soc. 2014, 136, 9308-9319.

12. Ait-Si-Ali, S.; Polesskaya, A.; Filleur, S.; Ferreira, R.; Duquet, A.; Robin, P.; Vervish, A.; Trouche, D.; Cabon, F.; Harel-Bellan, A. CBP/p300 histone acetyl-transferase activity is important for the G1/S transition. Oncogene 2000, 19, 2430-2437.

13. Iyer, N. G.; Xian, J.; Chin, S. F.; Bannister, A. J.; Daigo, Y.; Aparicio, S.; Kouzarides, T.; Caldas, C. p300 is required for orderly G1/S transition in human cancer cells. Oncogene 2007, 26, 21-29.

14. Mujtaba, S.; He, Y.; Zeng, L.; Yan, S.; Plotnikova, O.; Sachchidanand; Sanchez, R.; Zeleznik-Le, N. J.; Ronai, Z.; Zhou, M. M. Structural mechanism of the bromodomain of the coactivator CBP in p53 transcriptional activation. Mol. Cell 2004, 13, 251-263.

15. Prives, C.; Hall, P. A. The p53 pathway. J. Pathol. 1999, 187, 112-126.

16. Coutts, A. S.; La Thangue, N. B. The p53 response: Emerging levels of co-factor complexity. Biochem. Bioph. Res. Co. 2005, 331, 778-785.

17. Alarcon-Vargas, D.; Ronai, Z. p53-Mdm2 - the affair that never ends. Carcinogenesis 2002, 23, 541-547.

18. Wang, F.; Marshall, C. B.; Ikura, M. Transcriptional/epigenetic regulator CBP/p300 in tumorigenesis: structural and functional versatility in target recognition. Cell Mol. Life Sci. 2013, 70, 3989-4008.

19. Lavau, C.; Du, C. C.; Thirman, M.; Zeleznik-Le, N. Chromatin-related properties of CBP fused to MLL generate a myelodysplastic-like syndrome that evolves into myeloid leukemia. Embo J. 2000, 19, 4655-4664.

20. Pasqualucci, L.; Trifonov, V.; Fabbri, G.; Ma, J.; Rossi, D.; Chiarenza, A.; Wells, V. A.; Grunn, A.; Messina, M.; Elliot, O.; Chan, J.; Bhagat, G.; Chadburn, A.; Gaidano, G.; Mullighan, C. G.; Rabadan, R.; Dalla-Favera, R. Analysis of the coding genome of diffuse large B-cell lymphoma. Nat. Genet. 2011, 43, 830-837. 
21. Bedford, D. C.; Brindle, P. K. Is histone acetylation the most important physiological function for CBP and p300? Aging-Us 2012, 4, 247-255.

22. Hay, D. A.; Rogers, C. M.; Fedorov, O.; Tallant, C.; Martin, S.; Monteiro, O. P.; Müller, S.; Knapp, S.; Schofield, C. J.; Brennan, P. E. Design and synthesis of potent and selective inhibitors of BRD7 and BRD9 bromodomains. Med. Chem. Commun. 2015, 6, 1381-1386.

23. Middeljans, E.; Wan, X.; Jansen, P. W.; Sharma, V.; Stunnenberg, H. G.; Logie, C. SS18 Together with Animal-Specific Factors Defines Human BAF-Type SWI/SNF Complexes. PLOS one 2012, 7.

24. Kaeser, M. D.; Aslanian, A.; Dong, M. Q.; Yates, J. R.; Emerson, B. M. BRD7, a Novel PBAF-specific SWI/SNF Subunit, Is Required for Target Gene Activation and Repression in Embryonic Stem Cells. J. Biol. Chem. 2008, 283, 32254-32263.

25. Tae, S.; Karkhanis, V.; Velasco, K.; Yaneva, M.; Erdjument-Bromage, H.; Tempst, P.; Sif, S. Bromodomain protein 7 interacts with PRMT5 and PRC2, and is involved in transcriptional repression of their target genes. Nucleic Acids Res. 2011, 39, 5424-5438.

26. Kang, J. U.; Koo, S. H.; Kwon, K. C.; Park, J. W.; Kim, J. M. Gain at chromosomal region $5 \mathrm{p} 15.33$, containing TERT, is the most frequent genetic event in early stages of nonsmall cell lung cancer. Cancer Genet. Cytogen. 2008, 182, 1-11.

27. Scotto, L.; Narayan, G.; Nandula, S. V.; Subramaniyam, S.; Kaufmann, A. M.; Wright, J. D.; Pothuri, B.; Mansukhani, M.; Schneider, A.; Arias-Pulido, H.; Murty, V. V. Integrative genomics analysis of chromosome $5 \mathrm{p}$ gain in cervical cancer reveals target overexpressed genes, including Drosha. Mol. Cancer 2008, 7.

28. Zhou, J.; Ma, J.; Zhang, B. C.; Li, X. L.; Shen, S. R.; Zhu, S. G.; Xiong, W.; Liu, H. Y.; Huang, H.; Zhou, M.; Li, G. Y. BRD7, a novel bromodomain gene, inhibits G1-S progression by transcriptionally regulating some important molecules involved in ras/MEK/ERK and Rb/E2F pathways. J. Cell Physiol. 2004, 200, 89-98.

29. Wu, W. J.; Hu, K. S.; Chen, D. L.; Zeng, Z. L.; Luo, H. Y.; Wang, F.; Wang, D. S.; Wang, Z. Q.; He, F.; Xu, R. H. Prognostic relevance of BRD7 expression in colorectal carcinoma. Eur. J .Clin. Invest. 2013, 43, 131-140.

30. Park, Y. A.; Lee, J. W.; Kim, H. S.; Lee, Y. Y.; Kim, T. J.; Choi, C. H.; Choi, J. J.; Jeon, H. K.; Cho, Y. J.; Ryu, J. Y.; Kim, B. G.; Bae, D. S. Tumor Suppressive Effects of Bromodomain-Containing Protein 7 (BRD7) in Epithelial Ovarian Carcinoma. Clin. Cancer Res. 2014, 20, 565-575.

31. Burrows, A. E.; Smogorzewska, A.; Elledge, S. J. Polybromo-associated BRG1associated factor components BRD7 and BAF180 are critical regulators of p53 required for induction of replicative senescence. P. Natl. Acad. Sci. USA 2010, 107, 14280-14285.

32. Drost, J.; Mantovani, F.; Tocco, F.; Elkon, R.; Comel, A.; Holstege, H.; Kerkhoven, R.; Jonkers, J.; Voorhoeve, P. M.; Agami, R.; Del Sal, G. BRD7 is a candidate tumour suppressor gene required for p53 function. Nat. Cell Biol. 2010, 12, 380-389.

33. Mantovani, F.; Drost, J.; Voorhoeve, P. M.; Del Sal, G.; Agami, R. Gene regulation and tumor suppression by the bromodomain-containing protein BRD7. Cell Cycle 2010, 9, $2777-2781$.

34. Demont, E. H.; Bamborough, P.; Chung, C. W.; Craggs, P. D.; Fallon, D.; Gordon, L. J.; Grandi, P.; Hobbs, C. I.; Hussain, J.; Jones, E. J.; Le Gall, A.; Michon, A. M.; Mitchell, D. J.; Prinjha, R. K.; Roberts, A. D.; Sheppard, R. J.; Watson, R. J. 1,3-Dimethyl Benzimidazolones Are Potent, Selective Inhibitors of the BRPF1 Bromodomain. ACS Med. Chem. Lett. 2014, 5, 1190-1195.

35. Palmer, W. S.; Poncet-Montange, G.; Liu, G.; Petrocchi, A.; Reyna, N.; Subramanian, G.; Theroff, J.; Yau, A.; Kost-Alimova, M.; Bardenhagen, J. P.; Leo, E.; Shepard, H. E.; Tieu, T. N.; Shi, X.; Zhan, Y.; Zhao, S.; Barton, M. C.; Draetta, G.; Toniatti, C.; Jones, P.; 
Geck Do, M.; Andersen, J. N. Structure-Guided Design of IACS-9571, a Selective HighAffinity Dual TRIM24-BRPF1 Bromodomain Inhibitor. J. Med. Chem. 2015, DOI: 10.1021/acs.jmedchem.5b00405.

36. Bennett, J.; Fedorov, O.; Tallant, C.; Monteiro, O.; Meier, J.; Gamble, V.; Savitsky, P.; Nunez-Alonso, G. A.; Haendler, B.; Rogers, C.; Brennan, P. E.; Müller, S.; Knapp, S. Discovery of a Chemical Tool Inhibitor Targeting the Bromodomains of TRIM24 and BRPF. J. Med. Chem. 2015, DOI: 10.1021/acs.jmedchem.5b00458.

37. Ferguson, F. M.; Fedorov, O.; Chaikuad, A.; Philpott, M.; Muniz, J. R. C.; Felletar, I.; von Delft, F.; Heightman, T.; Knapp, S.; Abell, C.; Ciulli, A. Targeting Low-Druggability Bromodomains: Fragment Based Screening and Inhibitor Design against the BAZ2B Bromodomain. J. Med. Chem. 2013, 56, 10183-10187.

38. Rooney, T. P. C.; Filippakopoulos, P.; Fedorov, O.; Picaud, S.; Cortopassi, W. A.; Hay, D. A.; Martin, S.; Tumber, A.; Rogers, C. M.; Philpott, M.; Wang, M. H.; Thompson, A. L.; Heightman, T. D.; Pryde, D. C.; Cook, A.; Paton, R. S.; Müller, S.; Knapp, S.; Brennan, P. E.; Conway, S. J. A Series of Potent CREBBP Bromodomain Ligands Reveals an Induced-Fit Pocket Stabilized by a Cation-pi Interaction. Angew. Chem. Int. Ed. 2014, 53, 6126-6130.

39. Unzue, A.; Xu, M.; Dong, J.; Wiedmer, L.; Spiliotopoulos, D.; Caflisch, A.; Nevado, C. Fragment-based Design of Selective Nanomolar Ligands of the CREBBP Bromodomain $J$. Med. Chem. 2015, DOI: 10.1021/acs.jmedchem.1025b00172.

40. Drouin, L.; McGrath, S.; Vidler, L. R.; Chaikuad, A.; Monteiro, O.; Tallant, C.; Philpott, M.; Rogers, C.; Fedorov, O.; Liu, M. J.; Akhtar, W.; Hayes, A.; Raynaud, F.; Müller, S.; Knapp, S.; Hoelder, S. Structure Enabled Design of BAZ2-ICR, A Chemical Probe Targeting the Bromodomains of BAZ2A and BAZ2B. J. Med. Chem. 2015, 58, 25532559.

41. Chen, P.; Chaikuad, A.; P., B.; Bantscheff, M.; Bountra, C.; Chung, C.; Fedorov, O.; Grandi, P.; Jung, D.; Lesniak, R.; Lindon, M.; Müller, S.; Philpott, M.; Prinjha, R.; Rogers, C.; Selenski, C.; Tallant, C.; Werner, T.; Willson, T. M.; Knapp, S.; Drewry, D. H. Discovery and Characterization of GSK2801, a Selective Chemical Probe for the Bromodomains BAZ2A and BAZ2B. J. Med. Chem. 2015, DOI: 10.1021/acs.jmedchem.5b00209.

42. Clark, P. G. K.; Vieira, L. C. C.; Tallant, C.; Fedorov, O.; Singleton, D. C.; Rogers, C. M.; Monteiro, O. P.; Bennett, J. M.; Baronio, R.; Müller, S.; Daniels, D. L.; Mendez, J.; Knapp, S.; Brennan, P. E.; Dixon, D. J. LP99: Discovery and Synthesis of the First Selective BRD7/9 Bromodomain Inhibitor. Angew. Chem. Int. Ed. 2015, 54, 6217-6221.

43. Theodoulou, N. H.; Bamborough, P.; Bannister, A. J.; Becher, I.; Bit, R. A.; Che, K. H.; Chung, C.-w.; Dittmann, A.; Drewes, G.; Drewry, D. H.; Gordon, L.; Grandi, P.; Leveridge, M.; Lindon, M.; Michon, A.-M.; Molnar, J.; Robson, S. C.; Tomkinson, N. C. O.; Kouzarides, T.; Prinjha, R. K.; Humphreys, P. G. Discovery of I-BRD9, a Selective Cell Active Chemical Probe for Bromodomain Containing Protein 9 Inhibition. J. Med. Chem. 2015, DOI: 10.1021/acs.jmedchem.5b00256.

44. Kolb, P.; Kipouros, C. B.; Huang, D. Z.; Caflisch, A. Structure-based tailoring of compound libraries for high-throughput screening: Discovery of novel EphB4 kinase inhibitors. Proteins 2008, 73, 11-18.

45. Zhao, H.; Huang, D. Hydrogen bonding penalty upon ligand binding. PLOS one 2011, 6, e19923.

46. Zhao, H. T.; Dong, J.; Lafleur, K.; Nevado, C.; Caflisch, A. Discovery of a Novel Chemotype of Tyrosine Kinase Inhibitors by Fragment-Based Docking and Molecular Dynamics. ACS Med. Chem. Lett. 2012, 3, 834-838.

47. Unzue, A.; Dong, J.; Lafleur, K.; Zhao, H. T.; Frugier, E.; Caflisch, A.; Nevado, C. Pyrrolo[3,2-b]quinoxaline Derivatives as Types I-1/2 and II Eph Tyrosine Kinase Inhibitors: 
Structure-Based Design, Synthesis, and in Vivo Validation. J. Med. Chem. 2014, 57, 68346844.

48. Zhao, H. T.; Gartenmann, L.; Dong, J.; Spiliotopoulos, D.; Caflisch, A. Discovery of BRD4 bromodomain inhibitors by fragment-based high-throughput docking. Bioorganic \& Medicinal Chemistry Letters 2014, 24, 2493-2496.

49. Xu, M.; Unzue, A.; Dong, J.; Spiliotopoulos, D.; Nevado, C.; Caflisch, A. Discovery of CREBBP bromodomain inhibitors by high-throughput docking and hit optimization guided by molecular dynamics. J. Med. Chem. 2015, DOI: 10.1021/acs.jmedchem.1025b00171.

50. Zhao, H.; Caflisch, A. Discovery of ZAP70 inhibitors by high-throughput docking into a conformation of its kinase domain generated by molecular dynamics. Bioorg. Med. Chem. Lett. 2013, 23, 5721-5726.

51. Zhao, H.; Caflisch, A. Discovery of dual ZAP70 and Syk kinases inhibitors by docking into a rare C-helix-out conformation of Syk. Bioorg. Med. Chem. Lett. 2014, 24, $1523-1527$.

52. Zhao, H.; Gartenmann, L.; Dong, J.; Spiliotopoulos, D.; Caflisch, A. Discovery of BRD4 bromodomain inhibitors by fragment-based high-throughput docking. Bioorg. Med. Chem. Lett. 2014, 24, 2493-2496.

53. Zhao, H.; Huang, D.; Caflisch, A. Discovery of tyrosine kinase inhibitors by docking into an inactive kinase conformation generated by molecular dynamics. ChemMedChem 2012, 7, 1983-1990.

54. Zhao, H. T.; Dong, J.; Lafleur, K.; Nevado, C.; Caflisch, A. Discovery of a Novel Chemotype of Tyrosine Kinase Inhibitors by Fragment-Based Docking and Molecular Dynamics. Acs Med. Chem. Lett. 2012, 3, 834-838.

55. Fabian, M. A.; Biggs, W. H.; Treiber, D. K.; Atteridge, C. E.; Azimioara, M. D.; Benedetti, M. G.; Carter, T. A.; Ciceri, P.; Edeen, P. T.; Floyd, M.; Ford, J. M.; Galvin, M.; Gerlach, J. L.; Grotzfeld, R. M.; Herrgard, S.; Insko, D. E.; Insko, M. A.; Lai, A. G.; Lelias, J. M.; Mehta, S. A.; Milanov, Z. V.; Velasco, A. M.; Wodicka, L. M.; Patel, H. K.; Zarrinkar, P. P.; Lockhart, D. J. A small molecule-kinase interaction map for clinical kinase inhibitors. Nat. Biotechnol. 2005, 23, 329-336.

56. Quinn, E.; Wodicka, L.; Ciceri, P.; Pallares, G.; Pickle, E.; Torrey, A.; Floyd, M.; Hunt, J.; Treiber, D. Abstract 4238: BROMOscan - a high throughput, quantitative ligand binding platform identifies best-in-class bromodomain inhibitors from a screen of mature compounds targeting other protein classes. Cancer Res. 2013, 73, 4238.

57. Vidler, L. R.; Brown, N.; Knapp, S.; Hoelder, S. Druggability Analysis and Structural Classification of Bromodomain Acetyl-lysine Binding Sites. J. Med. Chem. 2012, 55, 73467359.

58. Brooks, B. R.; III, C. L. B.; Jr, A. D. M.; Nilsson, L.; Petrella, R. J.; Roux, B.; Won, Y.; Archontis, G.; Bartels, C.; Boresch, S.; Caflisch, A.; Caves, L.; Cui, Q.; Dinner, A. R.; Feig, M.; Fischer, S.; Gao, J.; Hodoscek, M.; Im, W.; Kuczera, K.; Lazaridis, T.; Ma, J.; Ovchinnikov, V.; Paci, E.; Pastor, R. W.; Post, C. B.; Pu, J. Z.; Schaefer, M.; Tidor, B.; Venable, R. M.; Woodcock, H. L.; Wu, X.; Yang, W.; York, D. M.; Karplus, M. CHARMM: The biomolecular simulation program. J. Comput. Chem. 2009, 30, 1545-1614.

59. Niesen, F. H.; Berglund, H.; Vedadi, M. The use of differential scanning fluorimetry to detect ligand interactions that promote protein stability. Nat. Protocols 2007, 2, 22122221 . 